\title{
Evidencialidade e polêmica em webcomentários em língua espanhola
}

\section{Evidentiality and controversial discourse in Spanish-language webcomments}

\author{
Victória Glenda Lopes Batista ${ }^{1}$, Nadja Paulino Pessoa Prata ${ }^{2}$, Léia Cruz de Menezes ${ }^{3}$ \\ ${ }^{1,2}$ Universidade Federal do Ceará, Brasil; ${ }^{3}$ Universidade da Integração Internacional da Lusofonia Afro-Brasileira, Brasil
}

Recebido em: 15/12/2019

Aceito em: $23 / 06 / 2020$

\begin{abstract}
RESUMO
Neste trabalho, objetivamos analisar qualitativamente o uso da evidencialidade nos discursos tidos como polêmicos, sob um enfoque funcionalista de análise, buscando integrar postulados teóricos da Gramática Discursivo-Funcional (GDF) com a noção de polêmica, constante em estudos de Análise de Discurso (AD) e de Argumentação Retórica. Conforme expresso em Hengeveld e Mackenzie (2008), a evidencialidade está relacionada à fonte da informação veiculada, ao passo que o discurso polêmico é entendido pela AD e pela Argumentação Retórica como um embate entre duas teses mutuamente excludentes, em geral, mas não obrigatoriamente, vinculadas à emotividade e à paixão. Acreditando que a marcação da evidencialidade é influenciada pela natureza polêmica dos discursos, buscamos, em webcomentários em língua espanhola, compreender o modo como a marcação da fonte é arregimentada pelos falantes de espanhol durante a argumentação em torno de tema polêmico. Constatamos que as fontes atuam na exemplificação de argumentos e no ataque a interlocutores com os quais o embate de ideias é travado, visando o descredenciamento do adversário. A evidencialidade mostrou-se característica do discurso polêmico.
\end{abstract}

PALAVRAS-CHAVE:

Evidencialidade. Argumentação. Polêmica. Webcomentários. Língua Espanhola.

\begin{abstract}
In this paper, we aim to qualitatively analyze the use of evidentiality in discourses considered as controversial, under a functionalist approach of analysis, seeking to integrate theoretical postulates of Discursive-Functional Grammar (GDF) with the notion of controversy, constant in Discourse Analysis studies (AD) and Rhetorical Argumentation. As expressed in Hengeveld and Mackenzie (2008), the evidentiality is related to the source of the information conveyed, whereas the controversial discourse is understood by DA and the Rhetorical Argumentation as a clash between two mutually exclusive theses, in general, but not necessarily, linked to emotionality and passion. Believing that the marking of evidentiality is influenced by the controversial nature of the speeches, we seek, in the Spanish-language webcomments, to understand how the marking of the source is regimented by the Spanish speakers during the argument about a controversial theme. We found that the sources act in exemplifying arguments and attacking interlocutors with which the clash of ideas is fought, aiming at the discrediting of the opponent. The evidentiality proved to be characteristic of the controversial discourse.
\end{abstract}

\footnotetext{
${ }^{1}$ E-mail: viviglenda@gmail.com |ORCID: 0000-0003-1709-2557.

${ }^{2}$ E-mail: nadjaprata@gmail.com|ORCID: 0000-0001-7861-7017.

${ }^{3}$ E-mail: leiamenezes@unilab.edu.br|ORCID: 0000-0001-5232-9711.
} 
KEYWORDS:

Evidentiality. Argumentation. Controversy. Webcomments. Spanish Language.

\section{Introdução}

O discurso polêmico, objeto de estudo de áreas como a Análise do Discurso e a Argumentação Retórica, é visto como espaço caracterizado por excessos e violência (AMOSSY, 2017), um espaço desprivilegiado, portanto, para o estudo dos meios linguísticos que se prestam à argumentação. A polêmica, no entanto, nas mídias em geral e especificamente na internet, se apresenta de maneira frequente, a tal ponto de se constituir em um dos contextos mais comuns de interação discursiva. Observamos que, por se caracterizar pelo antagonismo de duas teses que se excluem mutuamente, há, nesse tipo discursivo, uma recorrente marcação das fontes a serem (des)acreditadas. Assim, os falantes são levados a manipular diferentes tipos de fonte a fim de suscitar variados efeitos de sentido, na intenção de oferecer maior força argumentativa à tese que se pretende defender. Dessa observação, nasce nosso interesse de pesquisa: analisar o uso da fonte no discurso polêmico enquanto recurso argumentativo.

A evidencialidade, categoria que diz respeito à fonte da informação veiculada, tem sido estudada no arcabouço teórico da Gramática Discursivo-Funcional, que leva em consideração as intenções comunicativas do falante como geradoras do discurso e propõe uma análise da língua com base no contexto da interação e nos propósitos comunicativos dos falantes. Sendo assim, nos parece produtivo propor a união entre a categoria evidencialidade e a noção de polêmica, uma vez que, ao adotar os pressupostos teóricos disponíveis na Gramática Discursivo-Funcional, levaremos em consideração as intenções dos falantes, entre elas argumentar e debater, propósito este que pode ser esperado no discurso polêmico.

Trabalharemos com o gênero webcomentários, que, segundo Batista (2016) e Freitas (2012), já possui em sua natureza a característica de busca pela interação discursiva, uma vez prestar-se ao embate de opiniões, em torno de temáticas polêmicas. Trabalharemos com um corpus por nós constituído em língua espanhola, a fim de observar como os falantes de espanhol fazem uso das fontes como recurso argumentativo. Nosso trabalho se dividirá em cinco sessões: (i) explanações sobre a categoria evidencialidade; (ii) considerações acerca da polêmica no discurso; (iii) metodologia da pesquisa; (iv) análise e (v) considerações finais. 


\section{A categoria evidencialidade}

No arcabouço teórico-metodológico da Gramática Discursivo-Funcional (doravante, GDF), a evidencialidade, ou categoria evidencial, é entendida como concernente à fonte da informação constante numa dada sentença. Segundo Prata et al (2017, p.27), trata-se de uma "importante estratégia textual discursiva por meio da qual o falante marca a fonte da informação ou o modo de obtenção da informação".

Para ilustrarmos como a fonte atua discursivamente, tomemos os exemplos de Carioca (2011, p. 144): "Acredito que vai chover", "Acreditamos que vai chover", "O serviço de meteorologia disse que vai chover" e "Acredita-se que vai chover". As diferentes manipulações morfológicas das sentenças permitem interpretações diferentes. No primeiro exemplo, há um comprometimento pessoal do falante, marcando a sentença como uma opinião ou expectativa individual do sujeito (subjetivo). No segundo caso, a introjeção de outros participantes na construção da opinião propõe, segundo a autora, uma diluição da opinião do falante, reforçada pelo compartilhamento da expectativa com outros sujeitos (intersubjetivo). No terceiro exemplo, o sujeito afasta-se opinativamente do que é dito, utilizando uma fonte que espera fidedigna daquilo que está enunciando (o serviço de meteorologia). No último enunciado, a impessonalização dos sujeitos através de uma marca gramatical (se impessoal) confere à assertiva um caráter geral, comunitário, como uma opinião de um todo cultural. Desta forma, a autora considera que o uso de diferentes tipos de fonte caracteriza a evidencialidade como uma modalidade destinada à construção de diferentes efeitos de sentido.

No que diz respeito aos tipos de fonte evidencial, podemos pensá-las em termos de escalaridade de comprometimento/descomprometimento e aproximação/afastamento do falante à informação discursiva. De acordo com Carioca (2011, p. 155), é possível, portanto, estabelecer uma escala de maior para menor comprometimento, tendo (i) Sujeito Enunciador: o emissor do discurso se faz perceber como fonte, pelo uso da primeira pessoa do singular; (ii) Domínio Comum: o emissor se apresenta como fonte conjuntamente com seus ouvintes e demais participantes da troca discursiva, pelo uso de primeira pessoa do plural ou de terceira pessoa do singular junto à partícula SE (o que, para o espanhol, constitui-se na chamada pasiva refleja); (iii) Externa Definida: o emissor deixa claro sua não-inclusão como fonte, pelo uso da terceira pessoa de modo especificado; (iv) Externa Indefinida: não recuperável no contexto e dotada de aspecto 
mais impessoal. ${ }^{4}$ As fontes externas demandam acessos de informação menos diretos ou indiretos, isto é, estão mais relacionadas a uma interpretação dos fatos ou ao chamado "ouvi falar" (hearsay).

Nos trabalhos de Dall'Aglio-Hattnher (2012) e Hengeveld e Hattnher (2015), são descritas quatro naturezas para a fonte evidencial, em consonância com a arquitetura da GDF, a saber: (i) reportativa: se presta a uma simples descrição ou reprodução de material informativo alheio; (ii) inferencial: diz respeito à construção de uma informação a partir dos conhecimentos prévios do falante; (iii) perceptiva: está relacionada ao (não) testemunho do evento por parte do falante, e (iv) dedutiva: concerne à inferência do Estado-de-Coisas a partir de evidências acessíveis à informação. ${ }^{5}$

O componente evidencial da linguagem é recurso estratégico de legitimação discursiva. Assim, entendemos que essa categoria far-se-á constitutiva do discurso polêmico, uma vez que, em embates argumentativos, é preciso trazer força de autoridade ou de qualidade da informação, bem como faz-se necessário se valer de estratégias de descomprometimento que neutralizam a individualidade de opiniões, para que as palavras ganhem a força de um grupo, por exemplo. $\mathrm{Na}$ sequência, centraremos atenção nas características do discurso polêmico.

\section{Polêmica e discurso}

Para tratar de polêmica e discurso, nos valeremos do estudo de Amossy (2017) sobre a polêmica na argumentação e no debate. Para a autora, a polêmica sofre uma desvalorização no seio das linhas teóricas que a contemplam, a Análise do Discurso e a Argumentação Retórica, uma vez que esta estratégia está atrelada a conceitos de paixão e violência, desprivilegiando o caráter racional dos embates dialógicos e racionalizantes em busca de um dissenso e não de um consenso, como o fazem as demais estratégias discursivas. No entanto, Amossy (2017, p. 228) evoca a necessidade de uma maior atenção a se prestar à polêmica, uma vez ser ela sempre ventilada nas mídias e noticiada quando de seu acontecimento. Um evento discursivo que sempre tem espaço nas trocas linguísticas não deve ser desconsiderado quanto à sua importância.

Amossy (2017) afirma, no que é endossada por Indursky (1990), que a polêmica se cria

\footnotetext{
${ }^{4}$ Os exemplos dados acima foram considerados para o português. Observaremos, neste trabalho, se as mesmas marcações gramaticais se aplicam para a língua espanhola.

${ }^{5}$ O subtipo evidencial dedutivo foi inserido no trabalho de Hengeveld e Hattnher (2015), o qual também foi utilizado nas discussões do presente estudo.
} 
através de um antagonismo, isto é, através da delimitação de polos opinativos opostos, que se excluem mutuamente, e no qual cada um dos "partidários" de cada polo busca a adesão dos demais ouvinte e participantes da interação discursivas de modo a reforçar e garantir a veracidade ou maior razoabilidade do ponto que se busca defender.

De acordo com Brandão (1994, p. 2):

\begin{abstract}
A polêmica se instala quando há coexistência, num mesmo espaço discursivo, de dois pólos em torno dos quais se estruturam formações discursivas oponentes. Polemizar é, neste sentido, tentar falsear a fala do outro, é desqualificar o discurso do adversário numa situação em que duas posições antagônicas se confrontam e se afrontam.
\end{abstract}

Amossy (2017) problematiza o caráter polêmico ao afirmar que neste se encontram excessos que não necessariamente visam ao acordo entre partes de um debate. Para ela, o dissenso pode ser tão visado quanto o consenso pelos polemistas. A partir dessa problematização, Amossy (2017, p. 233) define o discurso polêmico com as seguintes características: surge como oposição a um discurso estabelecido previamente; apresenta dicotomização ou polarização da tese anterior, ou descrédito atribuído ao primeiro discurso ou à pessoa que o veiculou; recorre à paixão ou emoção, perceptíveis através da hostilidade presente entre os debatedores em polos antagônicos.

Amossy (2017, p. 233) propõe pensarmos a argumentação como um continuum, cuja centralidade é ocupada pelo debate racional de duas teses divergentes. Nesse continuum, persiste a ideia da veiculação de informações enquanto teses, sejam estas divergentes, eclipsadas ou antagonistas. A polêmica se caracteriza como discurso que não se presta à menção da tese prévia a ser atacada, tendo em vista uma valorização da que será defendida, ou o choque das posições antagonistas, mutuamente excludentes. A fonte da tese pode ser marcada ou apagada a depender do sentido que se deseja veicular e dos efeitos que se deseja alcançar, entre eles, o de adesão dos indivíduos às teses e/ou aos posicionamentos defendidos. Defendemos, então, a logicidade do uso da fonte da informação, contemplado pela categoria evidencial, como recurso de persuasão e argumentação, seja esta racional ou polêmica. Para este trabalho, nos interessa a polêmica.

Prosseguiremos, agora, na explanação de nossa metodologia de análise e escolha do corpus para este trabalho.

\title{
4. Metodologia
}

No que tange à metodologia, propomos uma análise qualitativa de webcomentários oriundos de um periódico espanhol de divulgação on-line, constituindo aproximadamente 10.000 
palavras, a fim de avaliar o modo em que os nativos da língua espanhola processam seus discursos e articulam suas expressões de âmbito evidencial em contextos informais de comunicação, bem como a construção da persuasão, uma vez que os comentários estudados apresentam um caráter predominantemente argumentativo, dado o contexto que integram. A construção deste corpus se deu em pesquisas anteriores para fins de estudo da modalidade deôntica em línguas espanhola. (BATISTA, 2013, 2016a, 2016b).

A razão de escolhermos o gênero webcomentário se explica pela natureza interativa deste, propícia ao debate e à polêmica. Os comentários que constituem o corpus são opiniões de seus respectivos autores em torno de tema abordado por textos jornalísticos na sessão Opinião. Nossa hipótese é que a categoria evidencialidade funcione como ferramenta recorrente aos falantes para incitar à polêmica ou apaziguá-la, atribuindo qualidade e força ao discurso.

Percorremos o nosso corpus e dele retiramos comentários que se caracterizam como polêmicos, em conformidade com as caraterísticas que Amossy (2017) apresenta como marcas do discurso polêmico, conforme já explicitado no tópico anterior. Como recorte para este artigo, escolhemos comentários em torno do texto de opinião intitulado ‘¿Expresión de una amenaza compuesta?'. ${ }^{6}$ O artigo, de autoria do Professor de Ciência Política da Universidade Rey Juan Carlos, Fernando Reinares, publicado no Jornal El País, discute o envolvimento conjunto de grupos terroristas em ataques, caracterizando o que o autor chamou de natureza composta adotada pelo terrorismo jihadista. Analisamos os efeitos de sentido gerados pela (não)marcação da fonte na construção, manutenção ou conclusão do discurso. Não nos valemos de programas estatísticos em nossa análise, nossa intenção é discutir como as fontes das informações são manipuladas pelos falantes nos comentários de nosso corpus.

\section{Análise e discussão}

A reflexão parte da notícia da prisão, na Espanha, de três indivíduos de origem turca e eurasiana, o que se apresenta como uma novidade, segundo o estudioso, pois a maioria dos presos na Espanha acusados de intenções terroristas são de outras nacionalidades.

Nos comentários, antagonizam-se as teses de que os que têm intenções terrorista são muçulmanos e esses são terroristas em potencial versus o oposto a essa tese. Analisamos os

\footnotetext{
6 Tradução: 'Expressão de uma ameaça composta?', disponível em: https://valverdedelcamino.net/politica/2012/08/02/actualidad/1343942685_140212.html Acesso: 12 dez. 2019.
} 
comentários quanto ao uso das fontes por parte de seus autores. Observamos a (não)marcação da fonte da informação como uma estratégia discursiva e persuasiva de (des)comprometimento do falante, em que este se aproxima ou se afasta da informação veiculada de modo a obter diferentes matizes de sentido.

Ressaltamos que nosso recorte será feito pela participação da comentarista Lisz, iniciadora da polêmica ao rechaçar a opinião expressa por Grossman. Este recorte se deve ao tamanho do debate, que se estende, e à necessidade de analisar detidamente o uso da (não)marcação de fonte como estratégia discursiva. Assim, a participação da comentarista Lisz no debate será nosso fio condutor. Vejamos:

(1)

grossmann

Todos tienen un nexo común: Son musulmanes. ¿Y quién los trajo a España? ¡ZP! ${ }^{7}$

ग1. lisz

Como no la culpa de del sr Zapatero, a ver quien hizo el ladrillazo? Aznar, quien pidió mano de obra para su ladrillazo Aznar, creo que se entiende bien quien trajo a quien y porque, solo tienes que ir a la hemeroteca de cualquier periodico para informarte, eso si tu ceguera intelectual te lo permite, según tu todos los musulmanes son terroristas es como decir que todos los españoles somos terroristas por tener a ETA o todos los irlandeses son tambien terroristas por el IRA,es facil de comprender que no conoces a ningún musulman para hablar así de todo un pueblo, ideas como las tuyas sobran porque son precisamente las que crean odio entre la gente, o tal vez sea eso lo que buscas crear discordia para seguir demonizando a todos musulmanes ${ }^{8}$

No exemplo (1), temos a instauração da polêmica: o falante Grossman instaura semelhança entre todos os que já foram presos na Espanha por práticas terroristas - todos são muçulmanos. Assim, acusa os muçulmanos de ameaça e o governante espanhol à época, Luis Zapatero (Fonte Externa Definida de caráter Reportativo), de responsável por ter a Espanha acolhido criminosos,

\footnotetext{
${ }^{7}$ Grossman - Todos têm um nexo comum: são muçulmanos. E quem os trouxe para a Espanha? ZP! (Nota: Zapatero, governante espanhol de 2004 a 2011).

${ }^{8}$ Lisz - Como assim a culpa é do sr. Zapatero, quem será que fez o jogo? Aznar (Nota: político liberal espanhol), quem pediu mão de obra para seu jogo Aznar, creio que se entende bem quem trouxe quem e por quê, tu só tens que ir à biblioteca de qualquer jornal para informar-te, isso se a tua cegueira intelectual te permitires, segundo tu todos os muçulmanos são terroristas é como dizer que todos nós espanhóis somos terroristas por ter o ETA (Nota: organização nacionalista espanhola) ou também que todos os irlandeses também são terroristas pelo IRA (Nota: organização similar à ETA), é fácil compreender por que tu não conhecer nenhum muçulmano para falar assim de todo um povo, ideias como as tuas sobram porque precisamente são elas que criam ódio entre as pessoas, ou talvez seja isso o que tu buscas criar discórdia para seguir demonizando a todos os muçulmanos.
} 
por ter facilitado a entrada do povo muçulmano ao país. A comentarista Lisz rebate, acusando o candidato liberal espanhol José María Aznar de manipulação política, suscitando-o como a fonte (Fonte Externa Definida de natureza Reportativa) de um pedido de mão de obra para o país.

Além disso, a falante Lisz acusa Grossman de generalizar os povos de maneira preconceituosa, reportando-o como uma fonte (Segundo tu - Fonte Externa Definida de tipo Reportativo - Grossman) de uma opinião depreciativa ("ideias como a tua são precisamente as que criam ódio entre a gente"), manipulando o que foi dito pelo comentarista como forma de acusá-lo. Entendemos que o uso de avatares e nomes fictícios atuam na proteção das imagens dos comentaristas, o que abre portas para declarações mais abertas e agressivas.

O embate prossegue:

(2)

serenityyy

Pues sí, todo musulman lleva dentro un terrorista en potencia. Seguir los mandatos de ese libro violento, intolerante y misogino convierte a todo mahometano en un peligro para los infieles. Un libro que dice estas barbaridades deberia ser prohibido en el mundo civilizado. Están autorizados a matar a los españoles y expulsarnos de aquí por haberlos echado de aqui hace 500 años:

-2:191 Matadles donde deis con ellos, y expulsadles de donde os hayan expulsado. Tentar es más grave que matar. No combatáis contra ellos junto a la Mezquita Sagrada, a no ser que os ataquen allí. Así que, si combaten contra vosotros, matadles: ésa es la retribución de los infieles. ${ }^{9}$

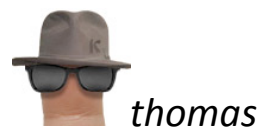

No saques las cosas de contexto, porque siguiendo esa misma regla de tres la Biblia tb tendría que estar prohibida. El 99.99 \% de los musulmanes no son terroristas. Igual que los vascos no son etarras. Seguir ese planteamiento de confundir (consciente o inconscientemente) la parte por el todo es, en realidad, lo que pretenden los terroristas, todos los terroristas"10

\footnotetext{
${ }^{9}$ Serenityyy - Sim, todo muçulmano tem dentro de si um terrorista em potencial. Seguir as ordens desse livro violento, intolerante e misógino converte todo maometano (Nota: Seguidor de Maomé) em um perigo para os infiéis. Um livro que diz estas barbaridades deveria ser proibido no mundo civilizado. Eles são autorizados a nos matar (aos espanhóis) e nos expulsar daqui por os termos expulsados há 500 anos: 2:191 Matem-nos onde quer que os encontrem, e os expulsem de ondem eles o expulsaram. Causar tentação é mais grave que matar. Não combatam contra eles próximo à Mesquita Sagrada, a não ser que eles o ataquem lá. Assim, se eles combatem contra vocês, matem-nos: essa é a retribuição aos infiéis.

${ }^{10}$ Thomas - Não retire as coisas do contexto, porque seguindo essa mesma regra de três a Bíblia também teria que ser proibida. 99, 99\% dos muçulmanos não são terroristas, assim como nem todos os bascos são membros da ETA. Seguir este plano de trocar (consciente ou inconscientemente) a parte pelo todo é o que, na realidade, querem os terroristas, todos os terroristas.
} 
No exemplo (2), o falante Serenityyy demonstra aderir à opinião expressa por Grossman, ao afirmar que 'todo muçulmano é um terrorista em potencial'. Serenityyy vale-se da Fonte Externa Reportativa, o Alcorão, texto sagrado muçulmano, que, de acordo com o falante, incitaria mulçumanos a matar infiéis. Para o comentarista, a fonte sagrada para as normas de conduta muçulmanas constitui, aparentemente, um argumento lógico, cuja conclusão é a de que todo mulçumano é, sim, imbuído do ideal terrorista. O falante não apenas faz menção ao texto sagrado, mas dele retira um excerto para corroborar a tese que defende.

No entanto, este é contestado pelo falante Thomas, que o acusa de tomar a parte pelo todo, o que, segundo ele, é uma lógica semelhante à adotado pelos terroristas. Neste ponto, temos uma não marcação da fonte de acusação, mas esta é plenamente recuperável pela natureza do gênero webcomentário, que se destina à expressão das opiniões dos falantes. Neste caso, o falante opta pela não marcação, quer pela não necessidade quer para atribuir-lhe força de senso comum.

Na sequência, Lisz retorna à discussão, dando continuidade à argumentação de Thomas e rebatendo Serenityyy, e nova comentarista, Radio_Gaga, entra em cena, fazendo Thomas retomar seu ponto de vista acerca da associação entre terrorismo e fanatismo religioso:

(3)

lisz

Deuteronomio 20:16-17, "Pero de las ciudades de estos pueblos que Jehová tu Dios te da por herencia, ninguna persona dejarás con vida, sino que los destruirás completamente las religiones monoteistas todas actuan igual pero eso no significa que todos sus fieles sean asesinos $^{11}$

radio_gaga

Mira, eso del capitalismo que induce al terrorismo, ya está mas que visto como excusa para lo inexcusable. Si la culpa es del capitalismo ¿porqué los terroristas no ponen las bombas en los grandes bancos, empresas que explotan a los pobres de esos países y demás? no nos engañemos a

\footnotetext{
${ }^{11}$ Lisz - Deuteronômio 20:16-17, “Mas nenhuma cidade destes povos que Jeová teu Deus te dá por herança, nenhuma pessoa tu deixará com vida, mas destruirás completamente as religiões monoteístas todas agem igual mas isso não significam que todos os seus fiéis são assassinos."
} 
nosotros mismos, los 200 muertos inocentes que se dirigían en tren a sus trabajos en España no eran capitalistas ni invasores, eran inocentes víctimas de tarados mentales. ${ }^{12}$

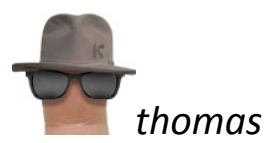

No te enteras contreras, los que hacen esos atentados no son tarados mentales, lee e infórmate mejor. Son extremistas religiosos. Igual que el noruego. Ese individuo no era un tarado mental si no un fanático. Te pones a escribir cosas de oídas. ${ }^{13}$

No exemplo (3), a participante Lisz endossa o raciocínio iniciado por Thomas, citando um trecho do livro sagrado dos cristãos, a Bíblia, a fim de demonstrar que esse livro também incitaria os que neles embasam sua vida a cometerem atos que podem ser considerados terroristas. Valendo-se de uma Fonte Externa Definida de tipo Reportativo (Bíblia), Lisz estabelece o argumento pela comparação: se o livro dos cristãos também alude ao assassinato dos infiéis, mas nem por isso os cristãos são vistos como terroristas, o mesmo raciocínio vale para os muçulmanos.

Neste entremeio, o qual retiramos por ausência de uso de fontes ou omissão delas com fins argumentativos, foco de nossa investigação, Lisz acusa o sistema capitalista de governo pelo modo como prejudica outros países e inviabiliza liberdades. Estabelece a comentarista uma relação de causa e consequência entre modos de agir do capitalismo e atos terroristas. Esse raciocínio de Lisz é veementemente rebatido por Radio_gaga, que afirma que o sistema capitalista não pode ser responsabilizado por ataques terroristas, pois, se assim o fosse, os ataques seriam contra instituições que representam o capitalismo, como os bancos e as grandes empresas, não recairiam sobre pessoas que se deslocam para o trabalho, como ilustra o falante. Radio_gaga afirma que ataques terroristas são cometidos por "doentes mentais" - estes não se voltam contra o sistema de governo, são insanos.

Thomas revela indignação ao uso do termo "doentes mentais" por Radio_gaga, contestando a qualidade da fonte das informações deste falante, exortando-o a 'ler e informar-se

\footnotetext{
${ }^{12}$ Radio_gaga - Olha, isso do capitalismo que induz ao terrorismo já está mais do que entendido como desculpa para o indesculpável. Se a culpa é do capitalismo, por que os terroristas não põem as bombas nos grandes bancos, empresas que exploram os pobres desses países entre outros? Não nos enganemos, os 200 mortos inocentes que iam de trem aos seus trabalhos em Espanha não eram capitalistas nem invasores, eram inocentes vítimas de doentes mentais.

${ }^{13}$ Thomas - Não fale do que não sabe, os que cometem esses atentados não são doentes mentais, lê e informa-te melhor. São extremistas religiosos. Igual ao norueguês. Esse indivíduo não era um doente mental, mas um fanático. Falas de coisas que só ouves falar.
} 
melhor'. Thomas descredencia Radio_gaga como interlocutor, ao afirmar que o comentarista fala daquilo que apenas "ouve falar" (Fonte Externa Indefinida de natureza Deduzida e acesso indireto - hearsay). Radio_gaga parece deduzir que os terroristas são doentes mentais a partir das informações a que teve acesso, não sendo estas uma fonte fidedigna, segundo Thomas. Ressaltamos neste exemplo uma recusa às fontes indefinidas de acesso indireto, pois, uma vez que não são identificáveis pelo contexto, estas parecem não possuir qualidade para os falantes, ao qual alude Thomas, considerando que estas informações apenas tenham sido repassadas sem critério, e que as informações de qualidade devem ser obtidas através da 'leitura e de uma melhor informação'.

(4)

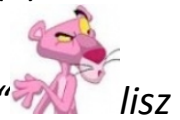

Primero no insultes, yo no te he faltado el respeto, no porque insultes vas a tener mas razon ${ }^{14}$

radio_gaga

Si te he insultado aún me he quedado corto, porque lo que tu dices es darle la razón a estos desalmados. ${ }^{15}$

No es de sorprender el cambio de perfil y comportamiento, porque es un hecho establecido y conocido que los organismo, tanto vivos, como institucionales y organizativos tienen instinto de conservación y supervivencia. Es lógico que se transformen para pasar desapercibidos. También que creen alianzas y modifiquen estrategias para conseguir los fines que persiguen. Los organismos de seguridad no deben bajar la guardia porque los planes terroristas no cesan y estas mentes criminales no duermen mucho tiempo ni se van de vacaciones."16

No exemplo (4), Lisz rebate a forma como Radio_gaga se contrapôs à sua fala, pedindo que o falante não a insulte. Radio_gaga, em sua resposta, retoma o dito pela participante Lisz (Fonte externa Definida Reportativa - Lisz) para afirmar que seu discurso favorece aos terroristas,

\footnotetext{
${ }^{14}$ Lisz - Primeiro não insultes, eu não te faltei o respeito, não é porque me insultas que vais a ter mais razão.

${ }^{15}$ Radio_gaga - Se eu te insultei inclusive porque me irritei, é porque o que tu dizes é dar razão a estes desalmados.

${ }^{16}$ H2oooh - Não é de surpreender a mudança de perfil e comportamento, porque é um fato estabelecido e conhecido que os organismos, tantos vivos, quanto institucionais e organizadores têm instinto de conservação e sobrevivência. É lógico que se transformem para passar despercebidos. Também que criem alianças e modifiquem estratégias para conseguir os fins que perseguem. Os organismos de segurança não devem baixar a guarda porque os planos terroristas não cessam e estas mentes criminosas não dormem muito tempo nem tiram férias.
} 
justificando, assim, o fato de havê-la insultado, por não compactuar com a posição ideológica de Lisz, pois esta, segundo Radio_gaga, "dá razão a desalmados". Neste ponto, Radio_gaga evoca todo o discurso proferido pela participante Lisz de forma a desacreditá-la, colocando-a como partidária ou amenizadora do povo muçulmano, que seria potencialmente perigoso e terrorista.

Tal argumentação é endossada pelo participante H2oooh, que evoca duas noções aparentemente compartilhadas por todos (Fonte Domínio Comum de natureza Inferida) ao dar a entender que todas as pessoas, a partir das experiências em sociedade, compartilham da noção de que os organismos buscam a conservação e a sobrevivência, adaptando-se para tanto por meio de alianças, a fim de defender que os planos terroristas buscam a sobrevivência e o fortalecimento, e que por isso os órgãos de defesa dos países não devem deixar de manter a atenção. Neste sentido, o participante $\mathrm{H}$ 2oooh parece evocar um senso comum, apelando para a racionalidade coletiva de uma verdade inerente aos seres vivos.

\section{Considerações finais}

A partir das falas analisadas, constatamos que a fonte atua como recurso recorrente no debate e no discurso polêmico. No caso específico dos webcomentários, percebemos uso frequente das fontes externas, uma vez que a natureza do gênero já prevê a manifestação da opinião dos falantes, boa parte dos comentários parece imbuídos destas, não havendo necessidade de sua marcação.

No que diz respeito ao uso das Fontes Externas, estas parecem ter sidos usadas com dois propósitos principais: o de exemplificar, como se deu nos casos das fontes políticas de caráter Reportativo e nos trechos citados de textos sagrados como o Alcorão e a Bíblia, que serviram de exemplo para as argumentações relativas ao terrorismo e aos povos muçulmano e cristão. Além disso, o uso da fonte externa se deu também como expediente retórico de acusação, permitindo aos falantes retomarem falas de seus 'antagonistas' de forma a desacreditá-los, como o fizeram a participante Lisz, ao considerar os argumentos de seus antagonistas como 'ideias que disseminam ódio entre as pessoas', o participante Thomas, que acusa o comentarista Radio_gaga de 'falar de coisas que só ouve falar', e o próprio Radio_gaga, ao considerar que o discurso Lisz 'dá razão aos desalmados'.

Concluímos, então, que a evidencialidade é recurso argumentativo no discurso polêmico, sendo usada, na maioria dos casos, como uso Reportativo, pelo qual os falantes recuperam discursos anteriores e deles se valem para garantir a qualidade de seu raciocínio argumentativo. 
Também ressaltamos que, nos excertos selecionados, aparentemente não se privilegiou um consenso nas opiniões expressas, senão no último exemplo, quando o participante H2oooh apelou para uma assertiva de senso comum a fim de recuperar uma espécie de racionalidade coletiva. Nenhum dos demais participantes pareceu buscar acordos, limitando-se a apresentar suas opiniões e desacreditar a opinião do outro, denegrindo, para tanto, o discurso ou a imagem de seu oponente.

\section{Referências}

AMOSSY, R. Por uma análise discursiva e argumentativa da polêmica. EID\&A: Revista de Estudos Integrados em Discurso e Argumentação. Ilhéus, n. 13, jan/jun 2017, p. 227-244.

BATISTA, V. G. L. A modalidade e o alvo deôntico em webcomentários: Uma análise funcionalista da língua espanhola. In: Anais dos encontros científicos: Unifor. Fortaleza, 2013.

BATISTA, V. G. L. A modalidade deôntica em webcomentários: Um estudo funcionalista da língua espanhola. In: MARTINS, M. A. et al. (Orgs.) Estudos linguísticos: Textos selecionados. ABRALIN 2013. João Pessoa. Ideia, 2016.

BATISTA, V. G. L. La modalidad deóntica en webcomentarios: un estudio funcionalista en lengua española. Trabalho de Conclusão de Curso (Graduação) - Universidade Federal do Ceará, Centro de Humanidades, Curso de Letras (Espanhol), Fortaleza, 2016.

BRANDÃO, H. H. N. Discurso e polêmica num debate político. Revista do Instituto de Estudos Brasileiros, n. 37, p. 129-143, 1994.

CARIOCA, C.R. Aspectos semânticos da evidencialidade nos trabalhos acadêmicos de grau. In: NOGUEIRA M. T.; LOPES M. F. V. (Orgs.). Modo e Modalidade: gramática, discurso e interação. Fortaleza: Edições UFC, 2011, p. 143-164.

DALL'AGLIO-HATTNHER, M. M. Gramática Discursivo-Funcional e os estudos tipológicos: um exercício de análise das línguas indígenas do Brasil. Estudos Linguísticos, v. 41, n. 1, p. 64-73, 2012.

FREITAS, E. O. Modalidade no gênero webcomentário do jornal O Povo: efeitos de sentido e relação com o inguí digital. 2012. 133 f. Dissertação (Mestrado em Linguística) - Programa de PósGraduação em Linguística, UFC. Fortaleza, 2012.

HENGEVELD, K. Illocution, mood, and modality. In: BOOIJ, G.; LEHMANN, C.; MUGDAN, J. (eds.). Morphology: a handbook on inflection and word formation. Berlin: Mouton de Gruyter, v. 2, 2004, p. 1190-1201.

HENGEVELD, K.; MACKENZIE, J. L. Functional Discourse Grammar: a typologically-based theory of language structure. Oxford: Oxford Linguistics, 2008.

HENGEVELD, K.; HATTNHER, M. M. D. Four types of evidentiality in the native languages of Brazil. Linguistics, v. 53, n. 3, p. 479-524, 2015.

INDURSKY, F. Polêmica e denegação: dois fundamentos discursivos da negação. Cadernos de estudos linguísticos. Campinas, SP. N. 19 (jul./dez. 1990), p. 117-122, 1990. 
PRATA, N. P. P. et al. A evidencialidade em textos jornalísticos escritos em língua espanhola. In:

PRATA, N. P. P. et al. (Orgs.). Espanhol em pauta: perspectivas teórico-analíticas. Curitiba, Appris, 2017.

\section{Agradecimento}

O presente trabalho foi realizado com apoio da Coordenação de Aperfeiçoamento de Pessoal de Nível Superior - Brasil (CAPES) - Código de Financiamento 001.

This study was financed in part by the Coordenação de Aperfeiçoamento de Pessoal de Nível Superior - Brasil (CAPES) - Finance Code 001. 